\title{
Effect of environmental parameters on culturability and viability of dust accumulated fungi in different HVAC segments
}

Liu, Zhijian; Yin, Hang; Ma, Shengyuan; Wei, Bing; Jensen, Benjamin; Cao, Guoqing

Published in:

Sustainable Cities and Society

Link to article, DOI:

10.1016/j.scs.2019.101538

Publication date:

2019

Document Version

Peer reviewed version

Link back to DTU Orbit

Citation (APA):

Liu, Z., Yin, H., Ma, S., Wei, B., Jensen, B., \& Cao, G. (2019). Effect of environmental parameters on culturability and viability of dust accumulated fungi in different HVAC segments. Sustainable Cities and Society, 48, [101538]. https://doi.org/10.1016/j.scs.2019.101538

\section{General rights}

Copyright and moral rights for the publications made accessible in the public portal are retained by the authors and/or other copyright owners and it is a condition of accessing publications that users recognise and abide by the legal requirements associated with these rights.

- Users may download and print one copy of any publication from the public portal for the purpose of private study or research.

- You may not further distribute the material or use it for any profit-making activity or commercial gain

- You may freely distribute the URL identifying the publication in the public portal 


\section{Accepted Manuscript}

Title: Effect of Environmental Parameters on Culturability and Viability of Dust Accumulated Fungi in Different HVAC Segments

Authors: Zhijian Liu, Hang Yin, Shengyuan Ma, Bing Wei, Benjamin Jensen, Guoqing Cao

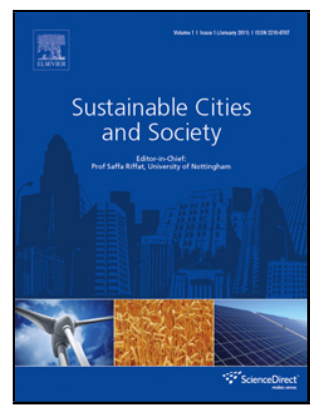

PII:

DOI:

S2210-6707(19)30311-7

Article Number: https://doi.org/10.1016/j.scs.2019.101538

Reference: 101538

To appear in:

Received date: $\quad 1$ February 2019

Revised date: $\quad 3$ April 2019

Accepted date: $\quad 4$ April 2019

Please cite this article as: Liu Z, Yin H, Ma S, Wei B, Jensen B, Cao G, Effect of Environmental Parameters on Culturability and Viability of Dust Accumulated Fungi in Different HVAC Segments, Sustainable Cities and Society (2019), https://doi.org/10.1016/j.scs.2019.101538

This is a PDF file of an unedited manuscript that has been accepted for publication. As a service to our customers we are providing this early version of the manuscript. The manuscript will undergo copyediting, typesetting, and review of the resulting proof before it is published in its final form. Please note that during the production process errors may be discovered which could affect the content, and all legal disclaimers that apply to the journal pertain. 


\section{Effect of Environmental Parameters on Culturability and Viability of Dust Accumulated Fungi in Different HVAC Segments}

Zhijian Liu ${ }^{1 *}$, Hang $\mathrm{Yin}^{2}$, Shengyuan $\mathrm{Ma}^{1}$, Bing $\mathrm{Wei}^{1}$, Benjamin Jensen ${ }^{2}$, Guoqing $\mathrm{Cao}^{3 *}$

${ }^{1}$ Department of Power Engineering, North China Electric Power University, Baoding, Hebei

071003, PR China

${ }^{2}$ Department of Civil Engineering, Technical University of Denmark, DK-2800 Kgs, Denmark

${ }^{3}$ Institute of Building Environment and Energy, China Academy of Building Research,

Beijing 100013, PR China

*Corresponding author: Zhijian Liu and Guoqing Cao

Email: zhijianliu@ncepu.edu.cn(Z.Liu);cgq2000@126.com(G.Cao)

\section{Highlights}

1. The relationships of fungal spore, cultivable and viable fungi in dust from HVAC system were explored.

2. Fungal culturability and viability in main segments of HVAC system were investigated.

3. The main factors of affecting culturable and viable fungi concentration were determined.

4. Predominant fungal species in deposition dust accumulation were identified. 


\begin{abstract}
Fungal contamination in dust accumulated on inner surface of the heating, ventilating, and air-conditioning (HVAC) systems has closely association with indoor human health. Dust samples were collected from 24 central HVAC system installed in office buildings in Beijing, China. The purpose of this paper is to investigate the distribution of fungal spore, culturable and viable fungi loading in five HVAC segments including the segments of fresh air, return air, mixture air, cooling and supply air. Fungal culturability and viability in dust samples collected from each sampling site were calculated and compared. The effects of environmental parameters and deposition dust loading on fungal concentrations, fungal culturability and viability were investigated by the Pearson correlation. In addition, predominant fungal species in deposition dust accumulation were identified, and its occurrence rates and relative abundances were also determined. These results could provide some useful information for fungal contamination control in HVAC system.
\end{abstract}

Keywords: Culturable fungi; Fungal culturability; Fungal viability; Dust deposition; Five HVAC segments

\title{
1. Introduction
}

The dust deposited in the heating, ventilating, and air-conditioning (HVAC) system of office buildings would be the source of fungal growth, and several fungi can produce 
spores and volatile organic compounds which bring adverse influence on indoor air and human health (Baxi et al., 2016; Chang et al., 1996; Batterman \& Burge, 1995; Mendell et al., 2006). Exposure to fungi for a long time would increase the risk of respiratory disease development, symptoms, and hypersensitivity (Baxi et al., 2016). In particular, indoor fungus exposure could be associated with asthma development for young children and the increase of asthma morbidity for asthmatics (Baxi et al., 2016; Meng, J., 2012). The increase of indoor contaminants may also be associated with building-related symptoms among occupants in office buildings, which would result in the reduction of work performance (Mendell, M. J., 2006). This means it is necessary to control the surface cleanliness of the HVAC ducts to prevent cross-contamination in public buildings. Zuraimi et al., systematically reviewed the concentrations of dust settled in duct surfaces in different types of buildings such as office buildings, school, residential buildings and so on, and indicated that the dust concentration at higher levels in office compared to residential buildings(Zuraimi, 2010). In addition, the HVAC systems are generally in long-term continuous working states in high-rise office building, so the air quality of air supply in HVAC system needs to be well controlled (Liu, 2019). The cleanliness of HVAC systems in Beijing, China deserves more attention due to the serious particulate pollution in outdoors (Wang, 2006) and long cleaning interval of HVAC system. High particulate concentration in outdoor air will increase the amount of dust accumulation in HVAC system. In addition, the phenomenon of not complying with the provisions to check and clean the HVAC system in time is commonly existed in China. Most of central air 
conditioning ventilation systems in office building are cleaned every two years.

Numerous studies have demonstrated many HVAC components including filters, heat exchangers, cooling coil, humidifiers or ducts, can act as direct or indirect sources of fungi(Waring \& Siegel, 2008; Noris et al., 2009; Liu et al., 2018; Liu et al., 2017; Meng et al., 2015). Dust deposited on the inner surface of these segments within HVAC system could provide enough nutrients for fungal growth. Further, the high humidity condition of some parts of HVAC system could provide enough water for fungal growth. Other factors such as temperature, air re-circulation, moist or wet insulation material can also be associated with higher levels of microorganisms(Noris et al., 2009; Chang et al., 1996; Foarde et al., 1996). Noris et al. investigated the concentration of bacterial and fungi (spores and culturable fungi) in the dust accumulated on the surface of HVAC filters (Noris et al., 2009; Noris et al., 2011; Forthomme et al. 2014; Perez et al. 2006). Some studies focused on the microorganism ecological distribution and contamination mechanism in supply air duct (Li et al., 2012; Li et al., 2010; Zuraimi 2010). Li et al. investigated the effect of temperature, relative humidity and supply air velocity on microbial growth in supply ducts (Li et al., 2010). Most previous researches mainly studied dust deposition and microbial contamination in one or several specific parts of HVAC system, it is hard to compare their results due to different sampling techniques, sampling methods, HVAC operation strategy, and other factors. Furthermore, the species and concentration of microorganisms in HVAC system also depend on both the indoor and outdoor 
microbial aerosol environment (Prussin et al., 2016; Adams et al., 2015). Some of the fungi are carried into HVAC system by fresh air, and some of the fungi are brought by the air re-circulated from the occupied space(Meadow et al., 2014). Perhaps this is why the previous papers always had different measurement results. However, very few studies measure the microorganism concentrations in multiple parts of the entire HVAC system (Zuraimi, 2010; Waring \& Siegel, 2008; Liu et al., 2015; Li et al., 2016; Lu et al., 2009). Only by comprehensively investigating the distribution of dust-associated fungi concentration in HVAC system can we have more targeted control strategies to reduce microbial contamination from source.

Not all fungal spores present in dust accumulated in HVAC ducts can be cultivated. Fewer than 5 percent of the total dust-associated fungi can grow on culture medium(Pasanen et al., 1997). There are still some of fungi which are viable but cannot be cultivated. In our research, dust-associated fungi are divided into three categories: fungal spores, culturable fungi and viable fungi. Fungi can grow and reproduce on culture medium, which is defined as 'culturable fungi'; while fungi identified by cell staining method defined is 'viable fungi'. Many studies have focused on the fungal spores and culturable fungi, while very few field investigations have been conducted to examine this 'viable fungi' in duct dust. In addition, there is no systematic standard to identify and quantify the duct surface contaminant levels in all the major HVAC segments. In China, only the mean dust loading and culturable fungi loading were considered as the important indicators of HVAC cleanliness 
(Ministry of Health of the People's Republic of China, 2012). Moreover, there is no set of limits for the concentration of fungi contamination in different parts of the air conditioning system. While National Air Duct Cleaners Association (NADCA) has published the International Standard entitled "Assessment, Cleaning, and Restoration of HVAC Systems" (NADCA The ACR Standard, 2015), which provide an annual inspection for major HVAC (heating, ventilation and air-conditioning) components (air handling unit, supply and return/exhaust ducts) within industrial building.

Twenty-four central air conditioning ventilation systems installed in office buildings in Beijing, China which were cleaned two years before this testing were selected to analyze the fungal contamination on the inner surface of HVAC systems. Dust samples were collected from five different locations in HVAC systems including the segments of fresh air, return air, mixture air, cooling and supply air. The objectives of this paper were: (i) to investigate the distribution of the total fungal spore loading, culturable fungi and viable fungi loading in different positions of HVAC systems; (ii) to analyze the culturability and viability of dust-associated fungi in different sampling sites and its influence factors, (iii) to examine the dominant dust-associated fungal species and compare their occurrence rate and relative abundance, (iv) to analyze environmental factors affecting fungal growth and the correlation relationship between dust loading, fungal spore, culturable fungi and viable fungi.

\section{Method}




\subsection{Sample collection}

Both Chinese Hygienic Standard (WS394-2012) and National Air Cleaners Association (NADCA) standard of "The Standard for the Assessment, Cleaning and Restoration of HVAC Systems" recommended that HVAC components in office buildings such as air handling units and supply, return and exhaust ducts should be inspected and cleaned up every year. However, it is common that most of central air conditioning ventilation systems are cleaned up every two years in Beijing, China. We selected twenty-four central HVAC systems installed in office buildings for this investigation which was cleaned two years before the testing. All HVAC filters haven't been changed or cleaned for two years. Therefore, the samples could represent the most serious pollution situation of HVAC system in Beijing, China. The minimum efficiency reporting value (MERV) of HVAC filters (ASHRAE, 2007) were different, nineteen air conditioning filters are low-efficiency with the MERV lower than 5, and five filters are mid-efficiency with the MERV in the range of 5 to 8 . The general Another possible reason information of HVAC system was shown in Table 1, which including building area, HVAC locations, Filter MERV, supply air volume and fresh air percentage. The structures of all the selected HVAC systems were the same, and the schematic diagram of sampling location in the HVAC system was shown in Fig.1. Dust sample collections were conducted in the cooling segment inside air handling units and four connected main ducts including return air segment, fresh air segment, mixture air segment and supply air segment. Meanwhile, environmental parameters including air temperature, air relative humidity and air velocity were also measured at 
each segment at the same time.

\section{Table 1}

General information of the selected HVAC systems.

\begin{tabular}{cccccc}
\hline No. & $\begin{array}{c}\text { Area } \\
\left(\mathrm{m}^{2}\right)\end{array}$ & HVAC sites & $\begin{array}{c}\text { Filter } \\
\text { MERV }\end{array}$ & $\begin{array}{c}\text { Supply air volume } \\
\left(\mathrm{m}^{3} / \mathrm{h}\right)\end{array}$ & $\begin{array}{c}\text { Fresh air percentage } \\
(\%)\end{array}$ \\
\hline 1 & 4515 & Roof & 1 & 22251 & 40.01 \\
2 & 8148 & Roof & 2 & 23428 & 46.18 \\
3 & 11088 & Roof & 3 & 24588 & 30.43 \\
4 & 15550 & Ground & 2 & 35127 & 35.58 \\
5 & 5852 & Roof & 1 & 18858 & 48.97 \\
6 & 9630 & Underground & 3 & 22018 & 43.73 \\
7 & 9702 & Ground & 2 & 22267 & 41.19 \\
8 & 4488 & Roof & 6 & 12089 & 33.75 \\
9 & 5928 & Roof & 1 & 18848 & 19.89 \\
10 & 16146 & Ground & 2 & 32069 & 30.01 \\
11 & 6292 & Underground & 3 & 22458 & 24.85 \\
12 & 3933 & Roof & 3 & 13587 & 34.67 \\
13 & 15425 & Ground & 1 & 35505 & 28.47 \\
14 & 8442 & Underground & 6 & 27522 & 32.92 \\
15 & 2014 & Underground & 1 & 10852 & 23.19 \\
16 & 2291 & Roof & 1 & 11205 & 21.15 \\
17 & 4650 & Underground & 7 & 8568 & 25.56 \\
18 & 9350 & Roof & 2 & 33255 & 33.67 \\
19 & 5778 & Ground & 1 & 24217 & 26.51 \\
20 & 6555 & Underground & 6 & 28199 & 30.32 \\
21 & 4628 & Underground & 1 & 12073 & 44.23 \\
22 & 8241 & Roof & 2 & 37545 & 41.15 \\
23 & 6336 & Underground & 7 & 26153 & 37.28 \\
24 & 7218 & Underground & 1 & 28949 & 34.63 \\
\hline
\end{tabular}

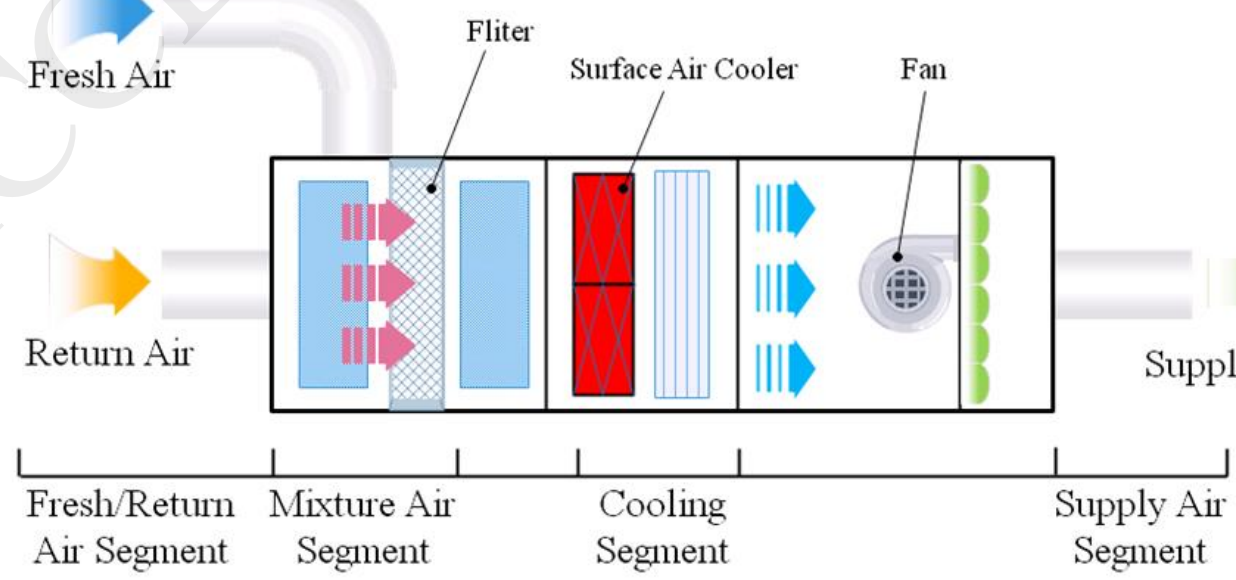


Fig. 1. The schematic diagram of sampling location in the HVAC system.

Field measurements were performed and dust samples were collected for further analyses from 6th July to 15th September in 2017. Test parameters covered in this measurement were air temperature, air relative humidity, air velocity, dust loading, fungi spore loading, culturable and viable fungi loading. Two parallel samplings were performed for each sampling point (Beijing Local Standard DB11/T 485-2007). The parameters of air temperature $\left({ }^{\circ} \mathrm{C}\right)$, air relative humidity $(\%)$ and air velocity $(\mathrm{m} / \mathrm{s})$ were measured by a TSI multi-channel portable tester (Model: 8392A) with the accuracy of $0.1{ }^{\circ} \mathrm{C}, 1 \%$ and $0.1 \mathrm{~m} / \mathrm{s}$, respectively. The dust samples were weighed by an electronic balance with the accuracy of 0.0001g (Model: 9367S). The weighing method of dust samples was based on the Chinese Hygienic Standard (WS394-2012). The surface dust sampling was evaluated by gravimetric wiping method. Before the sample, aseptic non-woven fabric $(100 \mathrm{~mm} \times 100 \mathrm{~mm})$ was placed into a sealed bag, coded and weighed twice. The average value was the initial weight. After wearing the disposable aseptic glove, the non-woven fabric held by tweezers was used to wipe all the dust accumulated at the bottom of the test segment corresponding to the sampling points. The non-woven fabric after sampling was put into the dryer for 24 hours and sealed in plastic bags. After weighted twice, the average value was the final value. Therefore, the difference between the final and initial weight of each set of non-woven fabrics was the accumulated dust loading of the sampling points, which was calculated as Eqs. (1).

$$
L_{d u s t}=\frac{\Delta M}{S}
$$

where $\mathrm{L}_{\text {dust }}\left(\mathrm{g} / \mathrm{m}^{2}\right)$ is the dust loading, $\Delta \mathrm{M}(\mathrm{g})$ is the difference of initial and final 
weight and $\mathrm{S}\left(\mathrm{m}^{2}\right)$ is the wiping area of the inner surface.

\subsection{Sample analysis}

Three sets of experiments were conducted to investigate the fungal spore, culturable and viable dust-associated fungi loading of each sampling site in HVAC system. For culturable fungi loading, the dust sample was extracted from non-woven fabric with $100 \mathrm{~mL} 0.01 \%$ Tween 80 (Sigma, USA) under sterile condition, stirred and shaken, and then $1 \mathrm{~mL}$ of extracts diluted 100-fold was inoculated to Sabouraud's Dextrose Agar dish. Each dilution of $100 \mathrm{~mL}$ was cultivated by three repetitions. According to the standard method for determining culturable fungi count in HVAC system (Chinese Hygienic Standard (WS394-2012)), the colony forming units of culturable fungi were counted after 5 days of incubation at $28^{\circ} \mathrm{C}$, and the culturable fungi loading was calculated by Eqs. (2).

$$
\mathrm{L}_{\text {culturable fungi }}=\mathrm{N}_{\text {culturable fungi }} \times 100 / \mathrm{S}
$$

where $\mathrm{L}_{\text {culturable fungi }}\left(\mathrm{CFU} / \mathrm{cm}^{2}\right)$ is the culturable fungi loading, $\mathrm{N}_{\text {culturable fungi }}(\mathrm{CFU})$ is the total number of colony forming unit fungi, and $\mathrm{S}\left(\mathrm{cm}^{2}\right)$ is the wiping area of inner surface. The reason why the formula was multiplied by 100 was because only $1 \mathrm{~mL}$ solution of $100 \mathrm{~mL} 0.01 \%$ Tween 80 dilution was incubated on a petri dish.

Fungal spore loading and viable fungi loading were evaluated by microscopic analysis. Following the above-described extraction and dilution process, $1 \mathrm{~mL}$ of extracts was filtered through a mixed cellulose ester membrane filter (A mixture of cellulose 
acetate and nitrocellulose, Aperture 1.2mm, Diameter 13mm, Millipore Corporation, Bedford, MA, USA). After that, the filter disk was made transparent by acetone vapor generated by a modified acetone-vaporizing unit (Model: Quixfix, Environmental monitoring system, Charleston, SC, USA). The sample was mounted by using glycerin jelly (gelatin: $20 \mathrm{~g}$, phenol crystals: $2.4 \mathrm{~g}$, glycerol: $60 \mathrm{~mL}$, sterile deionized water: $70 \mathrm{~mL}$ ) and stained for determining the fungal viability by acridine orange (AO) (Sigma-Aldrich, USA) and propidium iodide (PI) (Sigma-Aldrich, USA). The fungal spores and viable fungi were counted and identified by using a high-resolution light microscope (labophot 2, Nikon Corp.; Japan) in at least 40 microscopic fields at 100× or 400× magnification(Lee et al., 2006). Therefore, the fungal spore and viable fungi loading was calculated by Eqs. (3) and Eqs. (4), respectively.

$$
\begin{gathered}
\mathrm{L}_{\text {fungi spore }}=\mathrm{N}_{\text {fungi spore }} \times 100 / \mathrm{S} \\
\mathrm{L}_{\text {viable fungi }}=\mathrm{N}_{\text {viable fungi }} \times 100 / \mathrm{S}
\end{gathered}
$$

where $\mathrm{L}_{\text {fungal spore }}\left(\right.$ Spores $\left./ \mathrm{cm}^{2}\right)$ and $\mathrm{L}_{\text {viable fungi }}\left(\mathrm{CFU} / \mathrm{cm}^{2}\right)$ are the fungal spore and viable fungi loading, respectively, $\mathrm{N}_{\text {fungal spore }}$ (Spores) is the total number of fungal spores, and the $\mathrm{N}_{\text {viable fungi }}(\mathrm{CFU})$ is the number of colony forming unit fungi identified by the AO/PI stains.

The fungal culturability and viability are calculated by Eqs. (5) and (6), respectively.

$$
\begin{gathered}
\text { Culturability }=\mathrm{L}_{\text {culturable fungi }} / \mathrm{L}_{\text {fungi spore }} \\
\text { Viability }=\mathrm{L}_{\text {viable fungi }} / \mathrm{L}_{\text {fungi spore }}
\end{gathered}
$$

where the culturability $(\%)$ means the proportion of culturable fungi to the total fungal spores, corresponding the viability (\%) presents the proportion of viable fungi to the 
total fungal spores in the sampling site. In addition, the mean and standard deviation (SD) were used to describe the characteristics of data. The SPSS statistical packages (SPSS 16.0) were used for correlation analysis and Pearson's correlation coefficient (P) was used to study the relationship among environmental parameters, dust accumulation and fungal parameters. $\mathrm{P}$ values of $<0.05$ were considered as significant.

\subsection{Microorganism identification}

The fungal species were identified by the morphology method, which was employed in previous studies(Liu et al., 2015; Forthomme et al., 2014; Lu et al., 2009). The Sabouraud's Dextrose Agar dishes were examined by optical methods by an experienced analyst to identify and quantify the fungi growth on the Sabouraud's Dextrose Agar dishes. Identification was conducted according to morphological features of the fungi. Six most common fungal species were detected from dust samples including Penicillium, Aspergillus, Cladosporium, Alternaria, Mucor, and Trichoderma. An optical microscope (XSP-63B) and a fluorescent optical microscope (PF6200) were employed in this process. The fungal spores were observed by electron microscope.

\section{Results and discussion}

The range of air temperature, relative humidity and airflow velocity in return air segment, fresh air segment, mixture air segment, cooling segment and supply air segment of selected HVAC systems were summarized in Table 2, and the range of 
dust loading in each sampling site was also shown in Table 2. The ranges of air temperature were $23.9-29.3^{\circ} \mathrm{C}, 31.3-36.9^{\circ} \mathrm{C}, 26.7-29.9^{\circ} \mathrm{C}, 16.0-17.8^{\circ} \mathrm{C}$ and $19.0-21.2^{\circ} \mathrm{C}$ in return air segment, fresh air segment, mixture air segment, cooling segment and supply air segment, respectively. For each segment, the ranges of relative humidity were $47-59 \%, 64-70 \%, 56-70 \%, 87-91 \%$ and $73-79 \%$, respectively, and the ranges of airflow velocity were $6.1-7.3 \mathrm{~m} / \mathrm{s}, 2.3-3.9 \mathrm{~m} / \mathrm{s}, 2.9-3.7 \mathrm{~m} / \mathrm{s}, 1.5-2.3 \mathrm{~m} / \mathrm{s}$ and $5.3-6.5 \mathrm{~m} / \mathrm{s}$, respectively. Compared with other HVAC segments, the air temperature in fresh air segment was the highest while the lowest value occurred in cooling segment. In addition, relative humidity was the highest in cooling segment and the airflow velocity was the lowest in this segment when compared to other segments.

\section{Table 2}

Experimental results of environmental parameters and dust loading.

\begin{tabular}{lccccc}
\hline Mean \pm SD & Return Air & Fresh Air & Mixture Air & Cooling coil & Supply Air \\
\hline Temperature $\left({ }^{\circ} \mathrm{C}\right)$ & $26.6 \pm 2.7$ & $34.1 \pm 2.8$ & $28.3 \pm 1.6$ & $16.9 \pm 0.9$ & $20.1 \pm 1.1$ \\
Relative humidity $(\%)$ & $53 \pm 6$ & $67 \pm 3$ & $63 \pm 7$ & $89 \pm 2$ & $76 \pm 3$ \\
Airflow velocity $(\mathrm{m} / \mathrm{s})$ & $6.7 \pm 0.6$ & $3.1 \pm 0.8$ & $3.3 \pm 0.4$ & $1.9 \pm 0.4$ & $5.9 \pm 0.6$ \\
Dust loading $\left(\mathrm{g} / \mathrm{m}^{2}\right)$ & $16.12 \pm 3.68$ & $31.18 \pm 6.42$ & $25.14 \pm 5.32$ & $10.14 \pm 2.91$ & $6.20 \pm 2.29$ \\
\hline
\end{tabular}




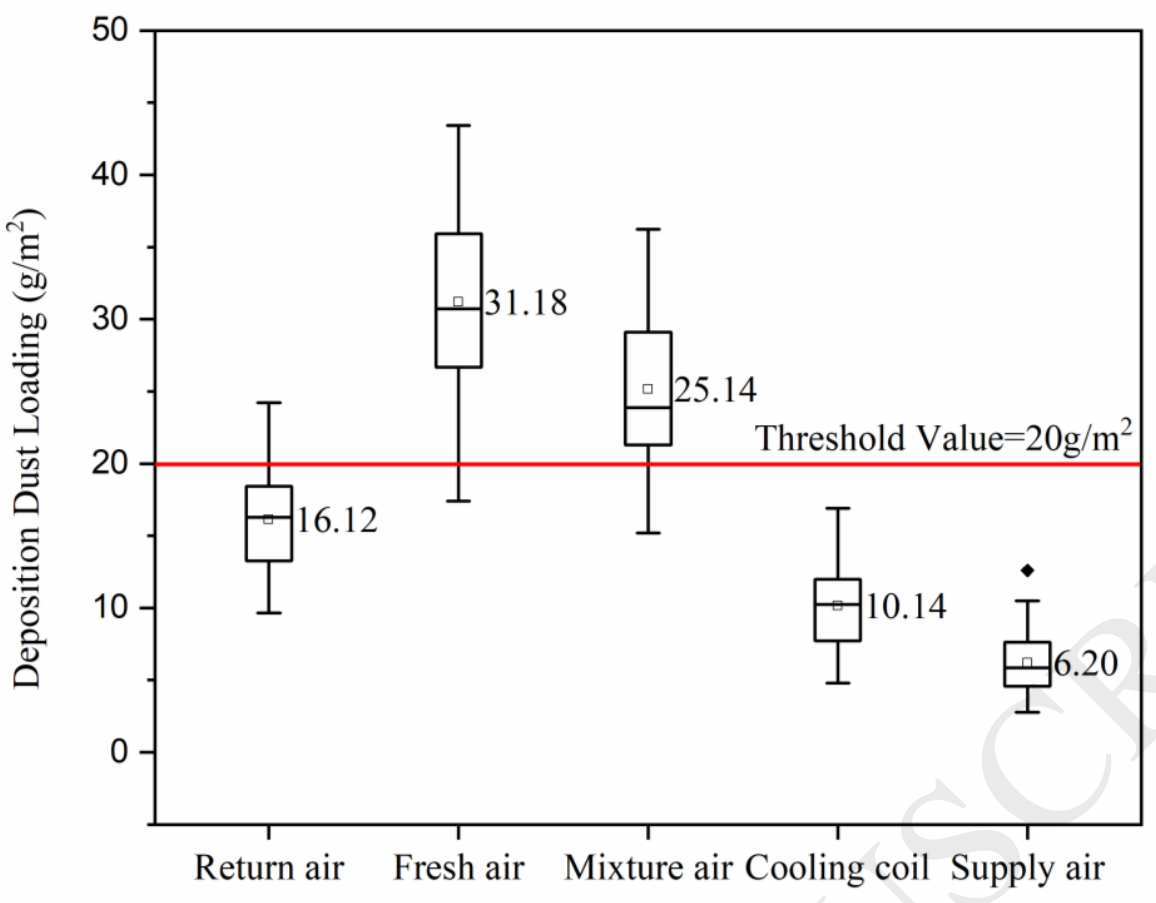

Fig. 2. The distribution of dust loading in five HVAC segments.

The dust loading of samples collected from different HVAC positions were shown in Fig.2. Chinese Hygienic standard (WS394-2012) suggested that the dust loading on inner surface of HVAC system should be less than $20 \mathrm{~g} / \mathrm{m}^{2}$. The mean dust loading in fresh air segments and mixture air segment were $31.18 \mathrm{~g} / \mathrm{m}^{2}$ and $25.14 \mathrm{~g} / \mathrm{m}^{2}$, respectively, both of them exceeded the threshold value of $20 \mathrm{~g} / \mathrm{m}^{2}$. The dust loading of 24 dust samples in supply air segments were in the range of $2.76 \mathrm{~g} / \mathrm{m}^{2}$ to $10.51 \mathrm{~g} / \mathrm{m}^{2}$, which was below the requirement. This means the HVAC filters can effectively reduce the particle concentration in outdoor air to ensure the amount of dust accumulated in supply air ducts within the allowable range. The dust loading in the return air segments was significantly higher than that of the supply air segments which indicated that there were some indoor particle sources(Bitter \& Fitzner, 2002; Meng et al., 2012; Bakó- Biró et al., 2004; Sarbu \& Sebarchievici, 2013; Wargocki et al., 2002;). 


\subsection{Fungal spore, culturable and viable fungi loading}

The comparison of fungi spore, culturable fungi and viable fungi loading in different HVAC segments was shown in Fig.3. The concentration and the fungi number per gram dust of fungi spore, culturable fungi and viable fungi in each sampling site were listed in Table 3 and Table 4, respectively.

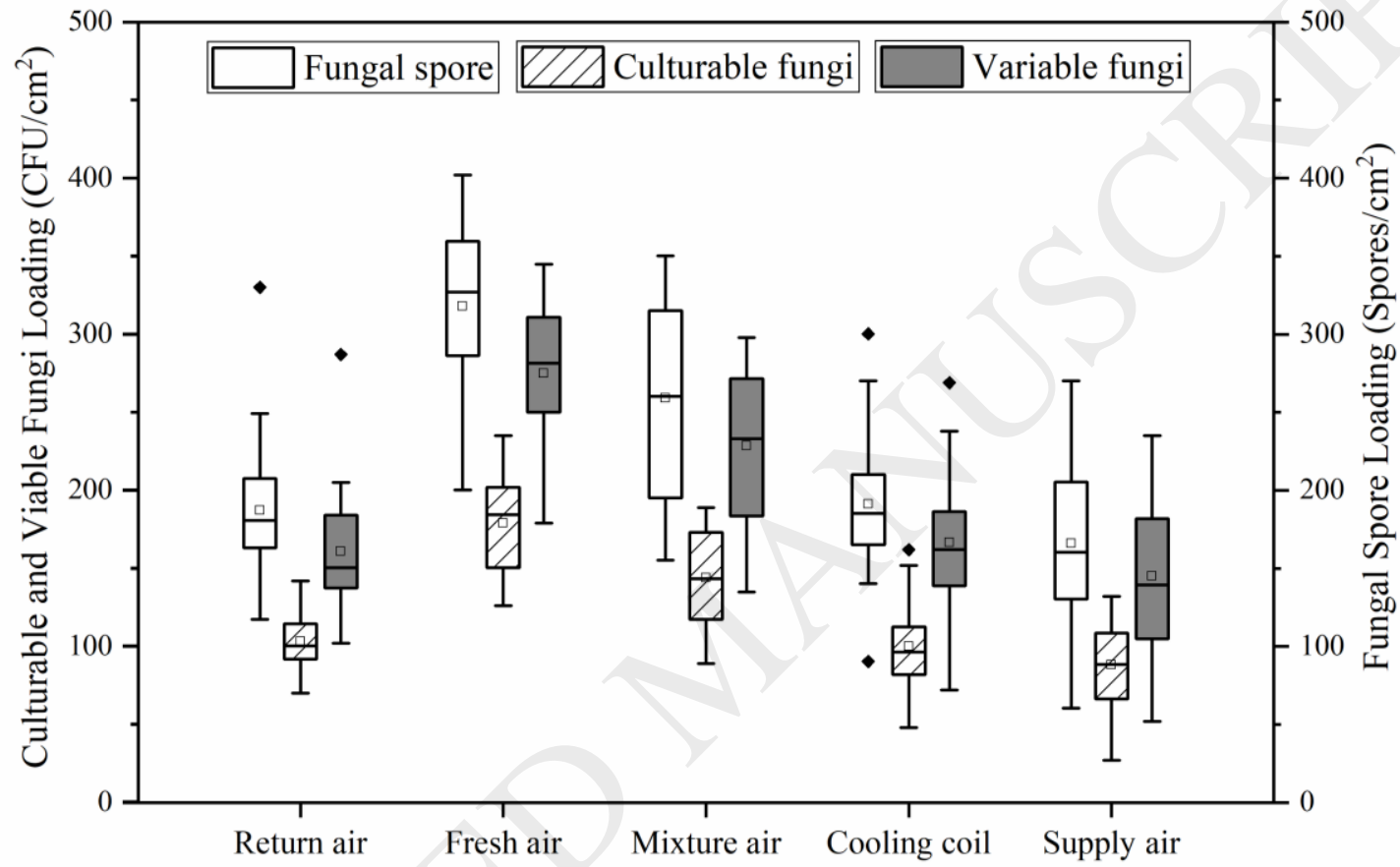

Fig. 3. Fungal spore, culturable fungi and viable fungi loading in HVAC system.

\section{Table 3}

The concentrations of fungal spore, culturable and viable fungi in sampling sites.

\begin{tabular}{cccccc}
\hline Mean \pm SD & Return Air & Fresh Air & Mixture Air & Cooling coil & Supply Air \\
\hline $\begin{array}{c}\text { Culturable fungi loading } \\
\left(\mathrm{CFU} / \mathrm{cm}^{2}\right)\end{array}$ & $103 \pm 20$ & $179 \pm 31$ & $144 \pm 33$ & $100 \pm 26$ & $88 \pm 27$ \\
$\begin{array}{c}\text { Viable fungi loading } \\
\left(\mathrm{CFU} / \mathrm{cm}^{2}\right)\end{array}$ & $161 \pm 41$ & $275 \pm 45$ & $229 \pm 50$ & $167 \pm 44$ & $145 \pm 50$ \\
$\begin{array}{c}\text { Fungal spore loading } \\
\left(\text { Spores } / \mathrm{cm}^{2}\right)\end{array}$ & $187 \pm 46$ & $318 \pm 53$ & $259 \pm 61$ & $191 \pm 48$ & $166 \pm 54$ \\
\hline
\end{tabular}

\section{Table 4}

The fungi number per gram dust of fungal spore, culturable and viable fungi in sampling sites.

Fungi number per gram $\quad$ Return Air $\quad$ Fresh Air $\quad$ Mixture Air $\quad$ Cooling coil $\quad$ Supply Air




\begin{tabular}{cccccc}
\hline dust $(\mathrm{CFU} / \mathrm{g})$ & \multicolumn{7}{c}{} & & \\
\hline Culturable fungi & 63896 & 57409 & 57279 & 98619 & 141935 \\
Viable fungi & 99876 & 88198 & 91090 & 164694 & 233871 \\
Fungal spore & 116005 & 101988 & 103023 & 188363 & 267742 \\
\hline
\end{tabular}

Chinese Hygienic standard (WS394-2012) suggested that the culturable fungi loading on inner surface of HVAC system should be less than $100 \mathrm{CFU} / \mathrm{cm}^{2}$. Except for in supply air segment, the culturable fungi loading in other HVAC segments exceeded this limitation, which means the cleanliness of selected HVAC systems cannot reach the standard. The distributions of fungal spore, culturable and viable fungi loading in different positions of HVAC system were generally the same. The loadings of fungal spore, culturable fungi and viable fungi all were the highest in fresh air segment, with the mean value of 318 Spores $/ \mathrm{cm}^{2}, 179 \mathrm{CFU} / \mathrm{cm}^{2}$, and $275 \mathrm{CFU} / \mathrm{cm}^{2}$ respectively, followed by that in mixture air segment, cooling segment, return air segment, and that in supply air segment were the lowest with the value of 166 Spores $/ \mathrm{cm}^{2}, 88 \mathrm{CFU} / \mathrm{cm}^{2}$, and $145 \mathrm{CFU} / \mathrm{cm}^{2}$ respectively. For HVAC segments of return air, fresh air and mixture air, the fungi number per gram dust of fungal spore, culturable fungi and viable fungi in different parts of HVAC were roughly the same. The mean values of fungal spore number per gram dust in these three segments were in the range of 101988-116005 CFU/g, for culturable fungi, the range of mean values was 57279-63896 CFU/g, and for viable fungi, the range of mean values was 88198-99876 $\mathrm{CFU} / \mathrm{g}$. While in cooling segment and supply air segment, the fungi number per gram dust of fungal spore, culturable fungi and viable fungi were significantly higher than that of in other parts of HVAC system. Generally, regarding fungal spore, culturable fungi and viable fungi, the mean value of fungi number per gram dust in cooling 
segment was about 1.7 times higher than in return air segment, fresh air segment and mixture air segment, furthermore, the mean value of fungi number per gram dust in supply air segment was about 2.5 times higher than in these three HVAC segments. High moisture conditions with the relative humidity of $76 \% \sim 89 \%$ in cooling segment and supply air segments was considered as a contributing factor to high fungal content in dust deposits. This view has also been confirmed from the results of Li et al (Li et al., 2012; Li et al., 2010). In cooling segment, there is a high potential risk of moisture condensation on the cooling coil surface. Condensed water can provide a habitat for fungal growth and also act as a source of airborne fungi downstream (Acerbi., 2016) Another possible reason was that low airflow velocity in cooling segment might reduce the possibility of fungal spore fragmentation; meanwhile, fungi spore could be easily deposited in this area and grow in the accumulated dust.

The differences between fungal spore loading, culturable and viable fungi loading in the same HVAC segment were compared. Most fungal spores were viable and can be stained. The difference between fungal spore and viable fungi loading in all HVAC segments was 20-30 CFU/ $\mathrm{cm}^{2}$ except in fresh air segment with the difference of 43 $\mathrm{CFU} / \mathrm{cm}^{2}$. Only part of viable fungi spores can grow on Sabouraud's Dextrose Agar dishes, so in each HVAC segment, the culturable fungi loading was lower than viable fungi loading and was also lower than fungal spore loading. The difference between fungal spore and culturable fungi loading in fresh air segment was the largest with the 
value of $139 \mathrm{CFU} / \mathrm{cm}^{2}$. After that, the difference in mixture air segment was the secondly largest with the value of $115 \mathrm{CFU} / \mathrm{cm}^{2}$, followed by that in cooling segment, return air and supply air segments. Among five different HVAC segments, the differences between fungal spore and culturable fungi loading were different, which could be explained by the different in dust loading and internal environment. The relationships between culturable and viable fungi loading, dust loading and environmental parameters would be further studied in the chapter of correlation analysis. Overall, only measuring the culturable fungi in dust sample from HVAC system will underestimate fungal allergen exposure because some viable fungal spores cannot be identified by direct cultivation. The study on fungi spore loading, viable fungi loading and culturable fungi loading would give a more comprehensive and detailed analysis of microbial contamination in HVAC system.

\subsection{Culturability and viability of fungi}

The culturability and viability of dust-associated fungi on the inner surface of the different HVAC segments was shown in Fig. 4 and the experimental data were listed in Table 5. Fungal viability of dust collected in the same sample sites was significantly higher than the fungal culturability. The range of fungal viability was from 86.15 to $88.65 \%$, while that of fungal culturability was from 52.53 to $56.66 \%$. In dust sample from HVAC segments of return air, fresh air and mixture air, the fungal viability was about 1.5 times of fungal culturability. While in cooling coil and supply air segment, the ratios of fungal viability to culturability were slightly higher with the 
values of 1.66 and 1.63 , respectively.

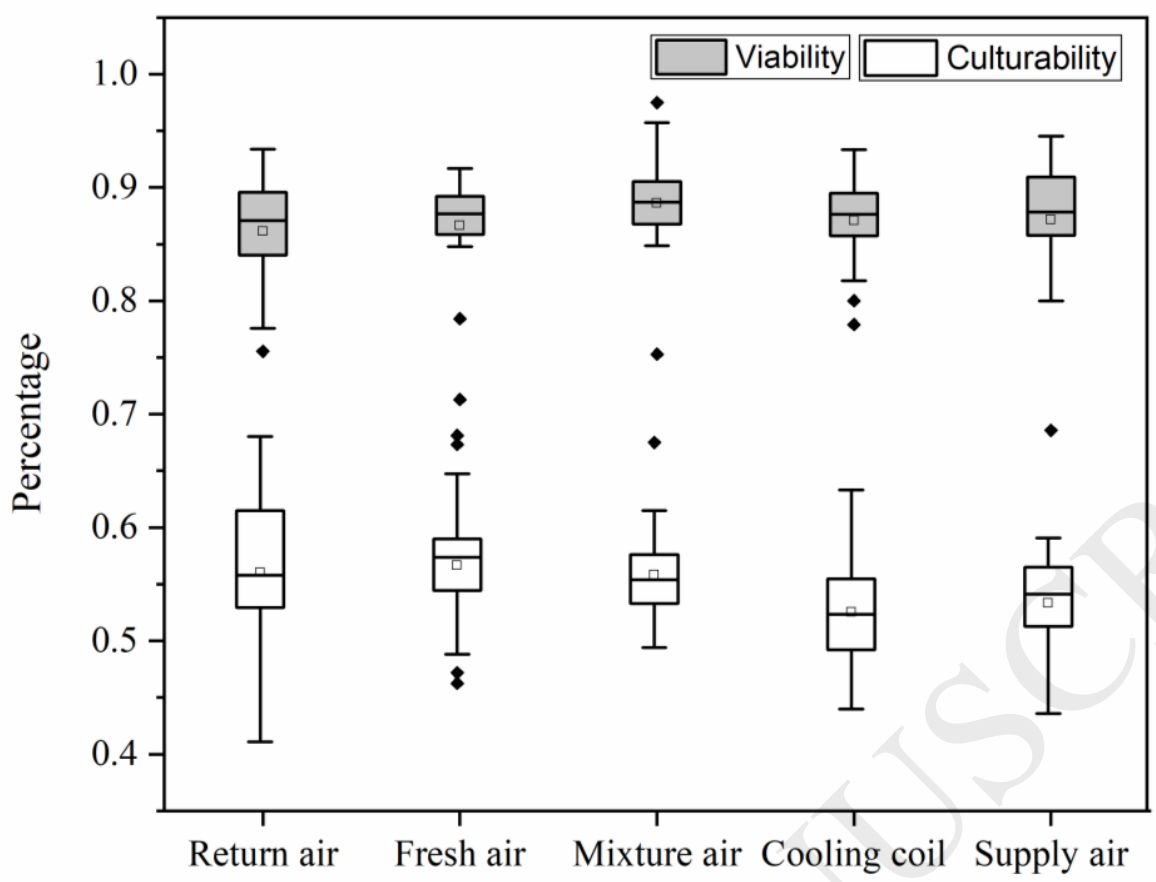

Fig. 4. Culturability and viability of dust-associated fungi on the inner surface of the different HVAC segments.

\section{Table 5}

Culturability and viability of dust-associated fungi.

\begin{tabular}{lccccc}
\hline Mean \pm SD & Return Air & Fresh Air & Mixture Air & Cooling coil & Supply Air \\
\hline Culturability $(\%)$ & $56.04 \pm 6.69$ & $56.66 \pm 5.72$ & $55.83 \pm 3.87$ & $52.53 \pm 4.61$ & $53.32 \pm 4.02$ \\
Viability (\%) & $86.15 \pm 4.72$ & $86.65 \pm 4.21$ & $88.65 \pm 4.20$ & $87.06 \pm 3.62$ & $87.16 \pm 5.36$ \\
Ratio of V/C & 1.54 & 1.53 & 1.59 & 1.66 & 1.63 \\
\hline
\end{tabular}

\subsection{Correlation analysis}

The relationships between environmental parameters, dust accumulation and fungal concentrations were analyzed by Pearson correlation, as shown in Table 6. In our study, the impacts of temperature and relative humidity on microorganism growth have been further confirmed. There was no significant correlation between dust loading and environmental parameters. However, the culturable and viable fungi loading were both positively correlated to temperature $\left(\mathrm{R}^{2}=0.5923, \quad p<0.05\right.$; 
$\mathrm{R}^{2}=0.4854, p<0.05$ ), while only the viable fungi loading was positively correlated to relative humidity $\left(\mathrm{R}^{2}=0.5261, p<0.05\right)$. Airflow velocity was not the direct factor of fungi loading in HVAC system. Many related studies shown that there was a significant positive correlation between microbial concentration and relative humidity and the effect of relative humidity on microbial concentration was greater than temperature and airflow velocity (Mui et al., 2008; Law et al., 2001). Minimizing the dust accumulation in HVAC segments which could provide high moisture condition and appropriate temperature for fungal survival would be the effective measures to reduce microbial contamination. Therefore, it is recommended that the interval time of HVAC cleanliness inspection schedule in cooling segment and supply air ducts should be shorter than that in other segments, for example, once or twice a year at a minimum.

Furthermore, there was a significant positive correlation between dust loading, culturable fungi loading, viable fungi loading and fungal spore loading $(p<0.05)$ in different segments of HVAC systems. The culturable fungi loading and fungal spore loading were both positively correlated to the dust loading $\left(\mathrm{R}^{2}=0.50523, p<0.05\right.$; $\mathrm{R}^{2}=0.47924, p<0.05$ ), so it is very essential to clean the HVAC ducts regularly in order to avoid accumulated dust providing survival condition for fungal growth. For culturable, viable fungi and fungal spore loading, there were moderate positive correlations among these three parameters with the value of $\mathrm{R}^{2}$ in the range from 0.4524 to $0.47536(p<0.05)$. Additionally, both fungal culturability and viability were positively correlated with temperature $\left(\mathrm{R}^{2}=0.4756, p<0.05 ; \mathrm{R}^{2}=0.4412, p<0.05\right)$, and 
the fungal viability was more sensitive to relative humidity with the $\mathrm{R}^{2}$ value of $0.4739(p<0.05)$. Fungal culturability was positively correlated with fungal viability $\left(\mathrm{R}^{2}=0.4891, p<0.05\right)$. Very few studies focused on the relationship between fungal culturability and viability. The results of this investigation suggested that culturable fungi was more sensitive to temperature, viable fungi was more sensitive to relative humidity, while the fungal spores more depends on dust accumulation, which provide some data for preventing microorganism growth in HVAC system. 


\section{Table 6}

The Pearson correlation among 9 measuring parameters.

\begin{tabular}{|c|c|c|c|c|c|c|c|c|c|}
\hline & Temperature & $\begin{array}{l}\text { Relative } \\
\text { humidity }\end{array}$ & $\begin{array}{l}\text { Airflow } \\
\text { velocity }\end{array}$ & Dust loading & $\begin{array}{c}\text { Culturable } \\
\text { fungi }\end{array}$ & $\begin{array}{c}\text { Viable fungi } \\
\text { loading }\end{array}$ & $\begin{array}{c}\text { Fungal } \\
\text { spore }\end{array}$ & Culturability & Viability \\
\hline Temperature & 1 & & & & & & & & \\
\hline Airflow velocity & -0.1218 & -0.2131 & 1 & & & & & & \\
\hline $\begin{array}{l}\text { Culturable fungi } \\
\text { loading }\end{array}$ & $0.5923^{*}$ & 0.3564 & -0.1232 & $0.50523 *$ & 1 & & & & \\
\hline Viable fungi loading & $0.4854^{*}$ & $0.5261 *$ & -0.1023 & 0.2013 & $0.4524 *$ & 1 & & & \\
\hline $\begin{array}{c}\text { Fungal spore } \\
\text { loading }\end{array}$ & 0.1232 & 0.1132 & -0.1859 & $0.47924 *$ & $0.47536^{*}$ & $0.4667^{*}$ & 1 & & \\
\hline
\end{tabular}

Annotation: Italicized values indicate a significant $(p<0.05$, 2-tailed) association between the paired variables 


\subsection{Fungal species identification}

Dust-accumulated fungal species vary both in taxa and concentration in different HVAC segments, and six predominant culturable fungi species from the dust accumulated in HVAC ducts were identified by the morphology method in the lab. The results of the occurrence rates and relative abundances for different culturable fungal species in five different HVAC segments were shown in Fig.5 and Fig.6, respectively, and the specific data were listed in Table 7.

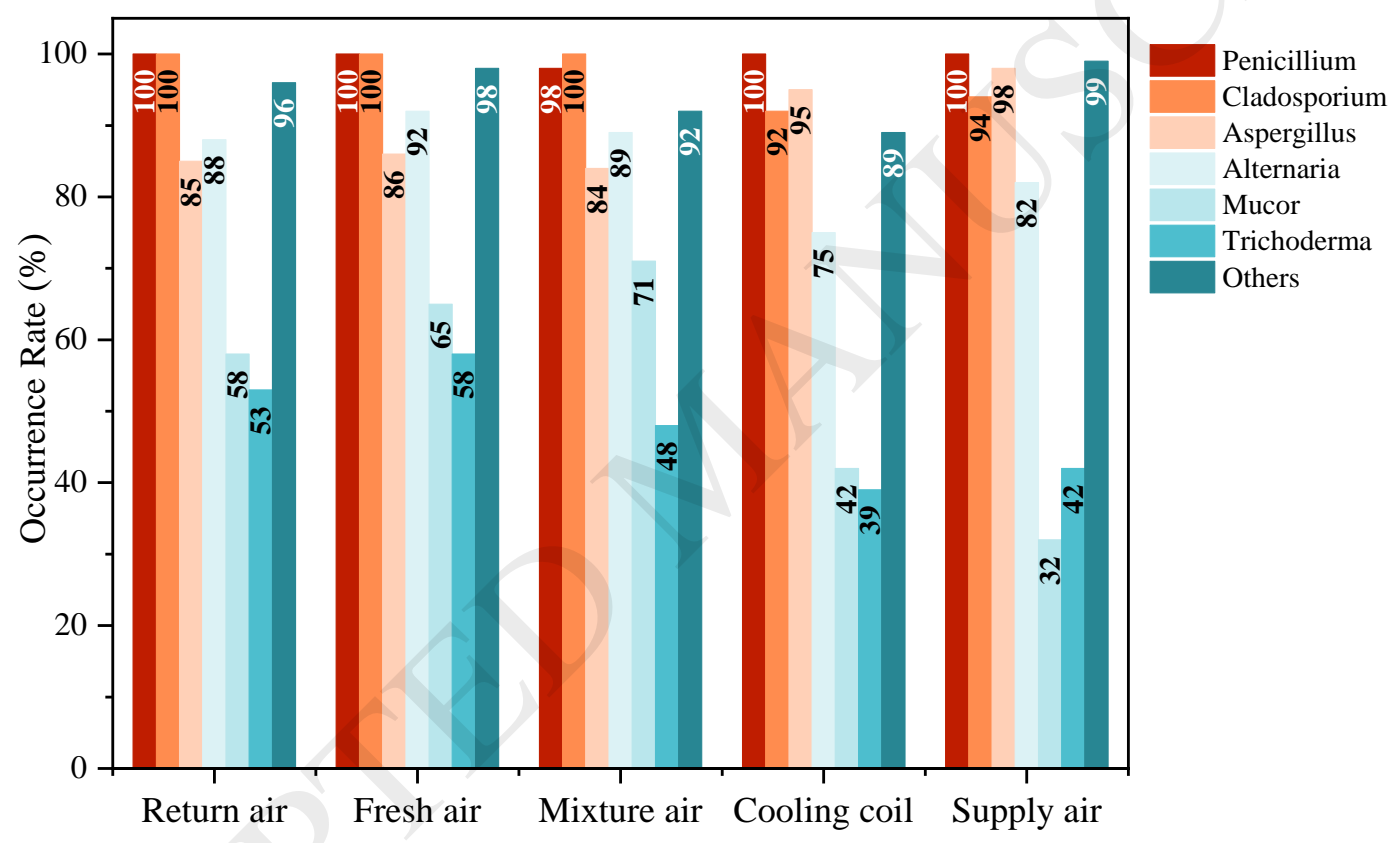

Fig. 5. The occurrence rates for different species of culturable fungi. 


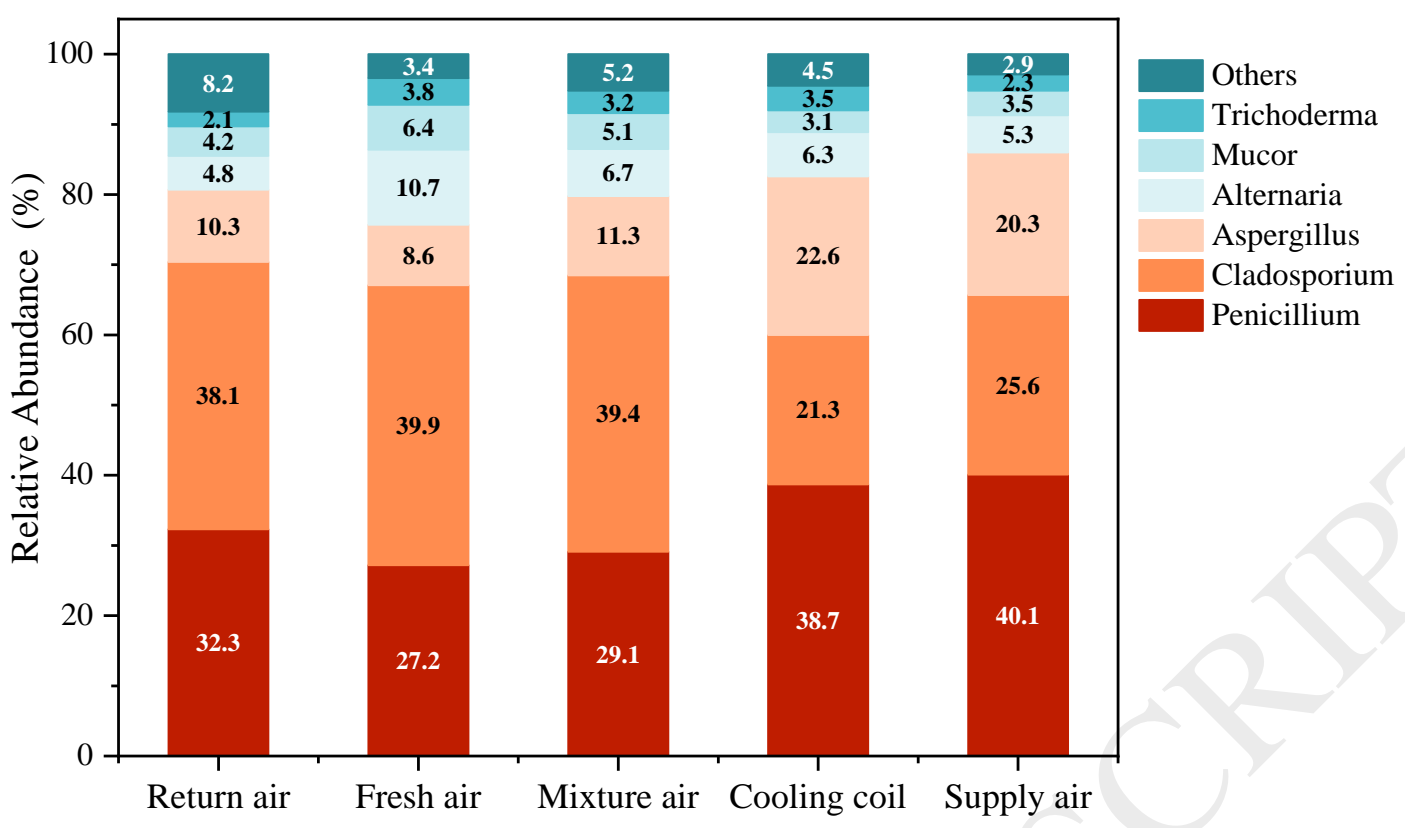

Fig. 6. The relative abundances for different species of culturable fungi.

Table 7

The occurrence rates and relative abundances for different species of culturable fungi.

\begin{tabular}{l|ccccc|ccccc}
\hline \multirow{2}{*}{ Species } & \multicolumn{4}{|c|}{ Occurrence rate (\%) } & \multicolumn{5}{|c}{ Relative abundance (\%) } \\
& $\mathrm{R}$ & $\mathrm{F}$ & $\mathrm{M}$ & $\mathrm{C}$ & $\mathrm{S}$ & $\mathrm{R}$ & $\mathrm{F}$ & $\mathrm{M}$ & $\mathrm{C}$ & $\mathrm{S}$ \\
\hline Penicillium & 100 & 100 & 98 & 100 & 100 & 32.3 & 27.2 & 29.1 & 38.7 & 40.1 \\
Cladosporium & 100 & 100 & 100 & 92 & 94 & 38.1 & 39.9 & 39.4 & 21.3 & 25.6 \\
Aspergillus & 85 & 86 & 84 & 95 & 98 & 10.3 & 8.6 & 11.3 & 22.6 & 20.3 \\
Alternaria & 88 & 92 & 89 & 75 & 82 & 4.8 & 10.7 & 6.7 & 6.3 & 5.3 \\
Mucor & 58 & 65 & 71 & 42 & 32 & 4.2 & 6.4 & 5.1 & 3.1 & 3.5 \\
Trichoderma & 53 & 58 & 48 & 39 & 42 & 2.1 & 3.8 & 3.2 & 3.5 & 2.3 \\
Others & 96 & 98 & 92 & 89 & 99 & 8.2 & 3.4 & 5.2 & 4.5 & 2.9 \\
\hline
\end{tabular}

Abbreviation: R-Return air segment; F-Fresh air segment; M-Mixture air segment; C-Cooling segment; S: Supply air segment.

The predominant culturable fungi were Penicillium, Aspergillus, Cladosporium and Alternaria in our study according to its high occurrences, which corresponding to the results of $\mathrm{Li}$ et al ( $\mathrm{Li}$ et al., 2012). While the results of $\mathrm{Lu}$ et al. indicated the predominant species were Cladosporium and Penicillium in AHU systems (Lu et al., 2009). Li et al. measured the concentrations of Penicillium, Aspergillus, Cladosporium, Alternaria, Mucor, and Trichoderma in supply air ducts, and the 
percentages of these fungi were $30.1 \%, 17.2 \%, 41.8 \% .5 .6 \%, 2.8 \%$ and $0.5 \%$, respectively(Li et al., 2012), while in our study, the percentages of these fungi were $40.1 \%, 20.3 \%, 25.6 \%, 5.3 \%, 3.5 \%$ and $2.3 \%$, respectively. Although there are some differences in details, the detected dominant species are the same.

The relative abundance of Cladosporium was highest in the fresh air segments when compared to other segments in HVAC system. That was because Cladosporium is the most frequently identified outdoor fungi, its spores are carried by fresh air into HVAC system (Pasanen et al., 1991). The relative abundance of Cladosporium dropped from $39.9 \%$ in fresh air segments to $25.6 \%$ in supply air segments, which is because of the filter applied in system, also is the high relative humidity in cooling segment (Zuraimi, 2010). The relative abundance and occurrence rate of other fungal species including Alternaria, Mucor and Trichoderma were similar with that of Cladosporium. No obvious difference was found in supply air and return air segments about the relative abundances of these fungi, so Cladosporium, Alternaria, Mucor and Trichoderma present in accumulated dust in HVAC systems were mainly from outdoor airborne fungal spores(Baxi et al., 2016). However, the relative abundances of Penicillium and Aspergillus were highest in cooling coil segments, which could be due to the micro-environment of the cooling segments provide suitable temperature and enough water for these fungi. The growth characteristics of this microorganism have been confirmed in previous studies(Baxi et al., 2016; Meng et al., 2012). Furthermore, Pasanen et al. noted that the airflow velocity would influence the fungal spore 
released into air, and Aspergillus and Penicillium spp. spores were released from their conidiophores at airflow velocity of $0.5 \mathrm{~m} / \mathrm{s}$ (Pasanen et al., 1991). Kanaani et al. found that higher air velocity would increase the fungal fragmentation, and the fungal fragmentation occurs when air velocity increased from $3.3 \mathrm{~m} / \mathrm{s}$ (Kanaani et al., 2009).Therefore, this further explain why the percentages of Aspergillus and Penicillium were highest in cooling segment, where the airflow velocity was lowest $(1.9 \mathrm{~m} / \mathrm{s})$ among the other segments of HVAC system (Return air: $6.7 \mathrm{~m} / \mathrm{s}$, Fresh air: $3.1 \mathrm{~m} / \mathrm{s}$, Mixture air: $3.3 \mathrm{~m} / \mathrm{s}$, Supply air: $5.9 \mathrm{~m} / \mathrm{s}$ ). Therefore, different measures and methods need to be taken to reduce the amount of different fungal species according to its growth conditions, such as inspecting and cleaning the cooling segment inside the air handling units before summer, shortening the cleaning time interval in HVAC system especially in fresh air segment and cooling segment, using HVAC filters with high efficiency and avoiding moisture condensation in cooling segment of the HVAC system and so on.

\section{Conclusions}

The distribution characteristics of dust loading, fungal spore, culturable and viable fungi in five major HVAC segments in office buildings were investigated in our study and the following conclusions could be drawn:

(1) The loadings of fungal spore, culturable fungi and viable fungi all were the highest in fresh air segment, followed by that in mixture air segment, cooling segment, return air segment and supply air segment. The fungi number per gram dust in cooling 
segment and supply air segments, the values were relatively higher than other segemnts.

(2) The range of fungal viability was from 86.15 to $88.65 \%$, while that of fungal culturability was from 52.53 to $56.66 \%$. The fungal viability was significantly higher than culturability with the ratio of 1.5 in return air, fresh air and mixture air segments and the ratio of 1.6 in cooling and supply air segments.

(3) Culturable fungi was positively correlated with temperature, viable fungi was more sensitive to relative humidity rather than temperature, and fungal spores more depends on dust accumulation $(p<0.05)$. There were moderate positive correlations between fungal spores, culturable fungi and viable fungi, with the value of $\mathrm{R}^{2}$ in the range from 0.4524 to $0.4754(p<0.05)$. The fungal culturability was positively and significantly correlated with fungal viability $(p<0.05)$, with the $\mathrm{R}^{2}$ value of 0.4891 .

(4) The predominant culturable fungi were Penicillium, Aspergillus, Cladosporium and Alternaria with high occurrence rates of $75 \%$. The relative abundances of Cladosporium, Alternaria, Mucor and Trichoderma were the highest in fresh air segments and were the lowest in supply air segments, which can be deduced that these fungi were mainly from outdoor airborne fungal spores. However, the fungal species of Aspergillus and Penicillium grow and propagate in high relative humidity and low airflow velocity conditions, so percentages of Aspergillus and Penicillium were highest in cooling coil.

(5) Some control strategies for fungal contamination in HVAC system are provided. The time interval of cleanliness in HVAC system should be once a year, for cooling 
segment and supply segment, the time interval of cleanliness can be further shortened. It is better to clean the dust accumulation in HVAC system before summer. Condensation in cooling segment or supply air segment should be avoided. High-efficiency air filters can be used to reduce dust accumulation in HVAC system, and fungi loading would also be controlled.

\section{Acknowledgment}

This work was funded by the National Science Foundation of China (No. 51708211), the National Key R\&D Program of China-Source identification, monitoring and integrated control of indoor microbial contamination (No. 2017YFC0702800), the Opening Funds of State Key Laboratory of Building Safety and Built Environment National Engineering Research Center of Building Technology (BSBE2017-08), Natural Science Foundation of Hebei (No. E2017502051) and Fundamental Research Funds for the Central Universities (No.2018MS103).

\section{References}

Acerbi E, Chénard C, Miller D, Gaultier NE, Heinle CE, Chang VW, Uchida A, Drautz- Moses DI, Schuster SC, Lauro FM. (2017). Ecological succession of the microbial communities of an air- conditioning cooling coil in the tropics. Indoor Air. 27(2):345-53.

Adams, R.I., Bhangar, S., Pasut, W., Arens, E.A., Taylor, J.W., Lindow, S.E., Nazaroff, W.W. and Bruns, T.D. (2015). Chamber bioaerosol study: outdoor air and human occupants as sources of indoor airborne microbes. PLoS One, 10(5), p.e0128022. 
ASHRAE A S. Standard 52.2-2007. Method of testing general ventilation air cleaning devices for removal efficiency by particle size. Atlanta: American Society of Heating, Refrigerating, and Air Conditioning Engineers;2007.

Bakó- Biró Z, Wargocki P, Weschler CJ and Fanger PO. (2004). Effects of pollution from personal computers on perceived air quality, SBS symptoms and productivity in offices. Indoor Air. 14, 178-187.

Batterman, S. A., \& Burge, H. (1995). HVAC systems as emission sources affecting indoor air quality: a critical review. HVAC\&R Research,1(1), 61-78.

Baxi, S. N., Portnoy, J. M., Larenas-Linnemann, D., Phipatanakul, W., Barnes, C., Baxi, S., ... \& Williams, P. B. (2016). Exposure and health effects of fungi on humans. The Journal of Allergy and Clinical Immunology: In Practice, 4(3), 396-404.

Bensch, K., Braun, U., Groenewald, J. Z., \& Crous, P. W. (2012). The genus cladosporium. Studies in mycology, 72, 1-401.

Bitter, F., \& Fitzner, K. (2002). Odour emissions from an HVAC-system. Energy and Buildings, 34(8), 809-816.

Brosseau, L. M., Vesley, D., Kuehn, T. H., Melson, J., \& Han, H. S. (2000). Methods and criteria for cleaning contaminated ducts and air-handling equipment. In 2000 ASHRAE Winter Meeting. ASHRAE.

Chang, J. C., Foarde, K. K., \& VanOsdell, D. W. (1996). Assessment of fungal (Penicillium chrysogenum) growth on three HVAC duct materials. Environment International,22(4), 425-431. 
Foarde, K.K., VanOsdell, D.W. \& Chang, J.C.S. (1996). Evaluation of fungal growth on fiberglass duct materials for various moisture, soil, use, and temperature conditions. Indoor Air, 6(2), 83-92.

Forthomme, A., Joubert, A., Andrès, Y., Simon, X., Duquenne, P., Bemer, D., \& Le Coq, L. (2014). Microbial aerosol filtration: Growth and release of a bacteria-fungi consortium collected by fibrous filters in different operating conditions. Journal of Aerosol Science, 72, 32-46.

Kanaani, H., Hargreaves, M., Ristovski, Z., \& Morawska, L. (2009). Fungal spore fragmentation as a function of airflow rates and fungal generation methods. Atmospheric Environment, 43(24), 3725-3735.

Law, A. K., Chau, C. K., \& Chan, G. Y. (2001). Characteristics of bioaerosol profile in office buildings in Hong Kong. Building and Environment, 36(4), 527-541.

Lee, T., Grinshpun, S. A., Martuzevicius, D., Adhikari, A., Crawford, C. M., \& Reponen, T. (2006). Culturability and concentration of indoor and outdoor airborne fungi in six single-family homes. Atmospheric Environment, 40(16), 2902-2910.

Li, A., Xiong, J., Yao, L., Gou, L. and Zhang, W. (2016). Determination of dust and microorganism accumulation in different designs of AHU system in Shaanxi History Museum. Building and Environment, 104, 232-242.

Li, A., Liu, Z., Liu, Y., Xu, X., \& Pu, Y. (2012). Experimental study on microorganism ecological distribution and contamination mechanism in supply air ducts. Energy and Buildings, 47, 497-505. 
Li, A., Liu, Z., Zhu, X., Liu, Y., \& Wang, Q. (2010). The effect of air-conditioning parameters and deposition dust on microbial growth in supply air ducts. Energy and Buildings, 42(4), 449-454.

Liu G., Xiao M., Zhang X., Gal C., Chen X., Lin L., Pan S., Wu J, Tang L, Croome D. C. (2017). A review of air filtration technologies for sustainable and healthy building ventilation. Sustainable Cities and Society, 32, 375-396.

Liu, Z., Ma, S., Cao, G., Meng, C., \& He, B. J. (2018). Distribution characteristics, growth, reproduction and transmission modes and control strategies for microbial contamination in HVAC systems: A literature review. Energy and Buildings, 177, $77-95$.

Liu Z, Liu Y, He B J, et al. (2019). Application and suitability analysis of the key technologies in nearly zero energy buildings in China[J]. Renewable and Sustainable Energy Reviews, 101, 329-345.

Liu, Z., Zhu, Z., Zhu, Y., Xu, W., \& Li, H. (2015). Investigation of dust loading and cultivable microorganisms of HVAC systems in 24 office buildings in Beijing. Energy and Buildings, 103, 166-174.

Lu, Z., Lu, W. Z., Zhang, J. L., \& Sun, D. X. (2009). Microorganisms and particles in AHU systems: Measurement and analysis. Building and Environment, 44(4), 694-698.

Mendell, M. J., Lei-Gomez, Q., Mirer, A., Seppanen, O., \& Brunner, G. (2006). Risk Factors in Heating, Ventilating, and Air-Conditioning Systems for Occupant Symptoms in US Office Buildings: the EPA BASE Study (No. LBNL-61870). 
Ernest Orlando Lawrence Berkeley NationalLaboratory, Berkeley, CA (US).

Meng C., Wang Q., Song Y., Cao Y., Zhao N. \& Shi Y. (2015). Experimental study on both cleaning effect and motion performance of the duct-cleaning robot. Sustainable Cities and Society, 14, 64-69.

Meng, J., Barnes, C. S., Rosenwasser, L. J., \& Children's Mercy Center for Environmental Health. (2012). Identity of the fungal species present in the homes of asthmatic children. Clinical \& Experimental Allergy, 42(10), $1448-1458$.

Chinese Hygienic standard WS 394-2012 (2012). Hygienic Specification of Central Air Conditioning Ventilation System in Public Buildings. Ministry of Health of the People's Republic of China, Beijing.

Meadow, J.F., Altrichter, A.E., Kembel, S.W., Kline, J., Mhuireach, G., Moriyama, M., Northcutt, D., O'Connor, T.K., Womack, A.M., Brown, G.Z. \& Green, J.L.(2014). Indoor airborne bacterial communities are influenced by ventilation, occupancy, and outdoor air source. Indoor air, 24(1), 41-48.

Mui, K. W., Wong, L. T., \& Hui, P. S. (2008). Risks of unsatisfactory airborne bacteria level in air-conditioned offices of subtropical climates. Building and environment, 43(4), 475-479.

NADCA (National Air Cleaners Association): ACR Standard 2015 Edition: The Standard for the Assessment, Cleaning and Restoration of HVAC Systems, Available at: http://acrstandard.nadca.com/

Noris, F., Siegel, J. A., \& Kinney, K. A. (2009). Biological and Metal Contaminants in 
HVAC Filter Dust. ASHRAE Transactions, 115(2).

Noris, F., Siegel, J. A., \& Kinney, K. A. (2011). Evaluation of HVAC filters as a sampling mechanism for indoor microbial communities. Atmospheric environment, 45(2), 338-346.

Pasanen, A. L., Kujanpää, L., Pasanen, P., Kalliokoski, P., \& Blomquist, G. (1997). Cultivable and Total Fungi in Dust Accumulated in Air Ducts in Single- Family Houses. Indoor Air, 7(2), 121-127.

Pasanen, A. L., Pasanen, P., Jantunen, M. J., \& Kalliokoski, P. (1991). Significance of air humidity and air velocity for fungal spore release into the air. Atmospheric Environment. Part A. General Topics, 25(2), 459-462.

Perez, H.R., Zimmerman, N.J. \& Berhane, Z. (2006). Evaluation of culturable particle load on HVAC filters before and after remediation: A pilot study. Indoor and Built Environment, 15(6), 525-533.

Prussin, A.J. and Marr, L.C. (2015). Sources of airborne microorganisms in the built environment. Microbiome, 3(1), 78.

Sarbu, I., \& Sebarchievici, C. (2013). Aspects of indoor environmental quality assessment in buildings. Energy and buildings, 60, 410-419.

Wargocki, P., Bakó-Biró, Z., Clausen, G., \& Fanger, P. O. (2002). Air quality in a simulated office environment as a result of reducing pollution sources and increasing ventilation. Energy and buildings, 34(8), 775-783.

Waring MS, Siegel JA. (2008). Particle loading rates for HVAC filters, heat exchangers, and ducts. Indoor Air, 18, 209-224. 
Wang, Y., Zhuang, G., Sun, Y. \& An, Z., (2006). The variation of characteristics and formation mechanisms of aerosols in dust, haze, and clear days in Beijing. Atmospheric Environment, 40(34), 6579-6591.

Zuraimi, M. S. (2010). Is ventilation duct cleaning useful? A review of the scientific evidence. Indoor Air, 20(6), 445-457. 